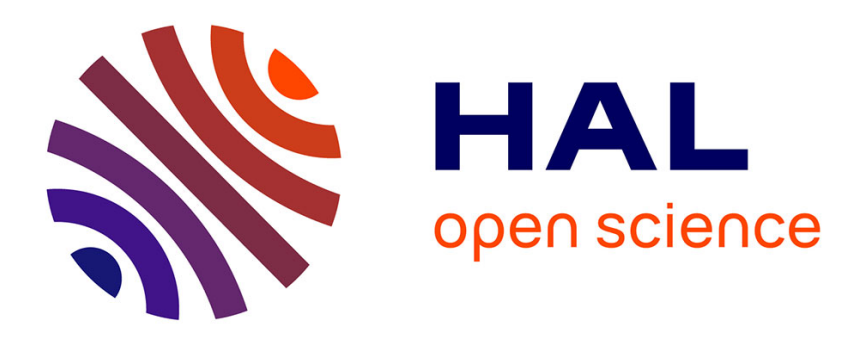

\title{
Influence of shock induced polymorphic transition on penetration in steel
}

\author{
P.-L. Hereil, A. Fanget
}

\section{To cite this version:}

P.-L. Hereil, A. Fanget. Influence of shock induced polymorphic transition on penetration in steel. Journal de Physique IV Proceedings, 1994, 04 (C8), pp.C8-263-C8-268. 10.1051/jp4:1994839 jpa00253394

\section{HAL Id: jpa-00253394 https://hal.science/jpa-00253394}

Submitted on 1 Jan 1994

HAL is a multi-disciplinary open access archive for the deposit and dissemination of scientific research documents, whether they are published or not. The documents may come from teaching and research institutions in France or abroad, or from public or private research centers.
L'archive ouverte pluridisciplinaire HAL, est destinée au dépôt et à la diffusion de documents scientifiques de niveau recherche, publiés ou non, émanant des établissements d'enseignement et de recherche français ou étrangers, des laboratoires publics ou privés. 


\title{
Influence of shock induced polymorphic transition on penetration in steel
}

\author{
P.-L. Hereil and A. Fanget \\ Centre d'Etudes de Gramat, 46500 Gramat, France
}

\begin{abstract}
The effects of polymorphic transition for the impact of a 27NCD10 steel projectile on a $27 \mathrm{NCD} 10$ steel target at $1280 \mathrm{~m} / \mathrm{s}$ is presented. Comparisons between results of $2 \mathrm{D}$ numerical calculations performed with and without polymorphic transition show the influence of this phenomenon on stress distribution and tension zones in the target and in the projectile. Good agreement between experimental and calculated free surface velocity profiles is obtained with polymorphic transition and damage models taken into account.

Résumé - Les effets de la transformation polymorphique dans le cas de limpact d'un projectile en acier $27 \mathrm{NCD} 10$ contre une cible en acier $27 \mathrm{NCD} 10$ à une vitesse d'impact de $1280 \mathrm{~m} / \mathrm{s}$ sont présentés. Les comparaisons entre les résultats des simulations numériques $2 \mathrm{D}$ réalisées avec et sans modèle de transformation polymorphique montrent linfluence de ce phénomène sur la distribution des contraintes et sur la localisation des zones de tension. Un bon accord entre les diagrammes de vitesse de surface libre expérimentaux et calculés a été obtenu en considérant un modèle de transformation polymorphique associé à un modèle d'endommagement.
\end{abstract}

\section{INTRODUCTION}

Since the shock-wave research of Bancroft et al. [1] on the polymorphic transition of iron, many investigators examined this $13,0 \mathrm{GPa}$ transition from bcc to hcp structure. Particularly, this transition was found in iron alloys and martensitic steels [2] [3] [4]. At the same time, a lot of theoretical works were done on the modelisation of this physical phenomena [5] [6] [7]. A review article by Duvall and Graham [8] gives the experimental and theoretical developments in this field.

In earlier papers [9] [10] [11], experimental and theoretical works on the direct and reverse polymorphic phase transitions of a low-alloy martensitic steel (27NCD10) have been presented. Experimental studies consist in plate impact configuration with a VISAR metrology. Direct and reverse phase transitions have been described by a phenomenological model in which thermodynamically consistent equations of state were used. This model has been implemented in a 1D wave propagation code and validated by comparison with experimental results. The present paper is the extension in $2 \mathrm{D}$ configuration of these previous studies. The objective is to show the influence of the polymorphic transition during the penetration of a steel projectile on a steel target at a velocity of $1280 \mathrm{~m} / \mathrm{s}$. In particular, we examine the effects of this phenomenon on the evolution of the damage in the target and in the projectile. 


\section{MODELS REVIEW}

\subsection{Polymorphic transition}

The constitutive relations consist in a two-phase equation of state and a thermodynamic model for the non-equilibrium phase change. The equilibrium surfaces of the first and second phase are characterized respectively by the Murnaghan's and Keane's equations of state. Their interdependence in the phase transition domain is realized by the equality of the Gibbs free energies of the two phases on the phase boundary. In formulating the model, the following physical assumptions are made :

- there is no surface energy associated with the phase interface,

-in the mixed phase region, pressure and temperature are common to both phases.

An internal parameter $\lambda$ is defined as the mass fraction of the second phase. The equilibrium functions $\lambda_{\text {eq }}$ for direct and reverse transition are respectively given by the expressions :

$$
\begin{aligned}
& \lambda_{\text {eq }}=1-\exp \left[\beta\left(G_{1}-G_{2}\right)\right] \\
& \lambda_{\text {eq }}=\exp \left[\beta\left(G_{1}-G_{2}\right)\right]
\end{aligned}
$$

where $\beta$ is a constant, $G_{1}$ and $G_{2}$ represent the Gibbs free energies of the two phases. The kinetics of the transformation are given by :

$$
\mathrm{d} \lambda / \mathrm{dt}=\left(\lambda_{\text {eq }}-\lambda\right) / \tau
$$

where $\tau$ is a relaxation time which is a function of the difference between the Gibbs free energies. The parameters of the model are recalled in table $I$.

\subsection{Damage}

A damage model for 27NCD10 steel based on the well known BFRACT model [12] has been proposed in an earlier paper [10]. Because of the difficulties of implementing this anisotropic damage model in 2D hydrocodes, we used an isotropic damage model for the calculations. This model proposed by Johnson [13] is available for ductile porous materials and we are aware of its limitations for brittle type damage for this steel. Nevertheless, this kind of model which is more sophisticated than a simple pressure cut-off criterium, will allow us to evaluate the damage in our studied configuration. The evolution of damage parameter $\mathrm{D}$ defined as the porosity, is given by:

$$
D=\frac{1}{2 \eta}\left(\frac{D_{0}}{1-D_{0}}\right)^{2 / 3} D^{1 / 3}(1-D)^{2 / 3}\left(P-P_{\text {eq }}\right)
$$

where a dot represents a time derivative, $\eta$ is a viscosity parameter, $D_{0}$ is the initial porosity and $P_{e q}$ is the equilibrium mean stress defined by the relation :

$$
P_{\text {eq }}(D)= \pm a_{z}(1-D) \log (1 / D)
$$

The parameter $a_{s}$ represents a threshold stress for damage growth. The values of the parameters reported in table II give the best fit of experimental data.

Table I

Parameters of the polymorphic transition model

\begin{tabular}{lcc}
\hline & first phase & second phase \\
\hline Isothermal bulk modulus $\mathrm{K}_{0}(\mathrm{GPa})$ & 15.5 & 21.5 \\
Murnaghan's parameter $\mathrm{n}_{0}$ & 5.5 & 6.5 \\
Keane's parameter $\mathrm{n}_{\mathrm{i}}$ & -- & 4.5 \\
Specific heat $\mathrm{C}_{\mathrm{v}}(\mathrm{J} / \mathrm{kg} / \mathrm{K})$ & 444.7 & 446.6 \\
Grüneisen coefficient $\Gamma_{0}$ & 1.735 & 2.0 \\
$\beta(\mathrm{kg} / \mathrm{J})$ & $9.10^{-5}$ & $9.10^{-5}$ \\
\hline
\end{tabular}


Table II

Parameters of the damage model

\begin{tabular}{lc}
\hline initial porosity $\mathrm{D}_{0}$ & 0.0003 \\
viscosity $\eta$ (Poise) & 40 \\
mean stress threshold $\mathrm{a}_{\mathrm{s}}(\mathrm{GPa})$ & 0.25 \\
\hline
\end{tabular}

\section{EXPERIMENTAL CONFIGURATIONS}

\subsection{Material properties}

The investigated material is a low-alloy martensitic steel fabricated by rolling. Alloying agents and impurities are (in wt\%) : C (0.270), $\mathrm{Mn}(0.670), \mathrm{Ni}(2.24), \mathrm{Cr}(2.16), \mathrm{Cu}(0.17), \mathrm{Mo}(0.48)$ and others $(0.01)$. Its Rockwell $\mathrm{C}$ hardness is approximatively 25 and its density is $7835 \mathrm{~kg} / \mathrm{m}^{3}$. Ultrasonic measurement yields mean values of longitudinal $C_{L}$ and shear $C_{S}$ wave velocities : $C_{L}=5895 \mathrm{~m} / \mathrm{s}$ and $C_{S}=3225 \mathrm{~m} / \mathrm{s}$. The corresponding value for Poisson's ratio is $v=0.286$.

\subsection{Studied configurations}

The experimental configuration consists in the impact at $1280 \mathrm{~m} / \mathrm{s}$ of a $27 \mathrm{NCD} 10$ steel projectile with a flat noze against a $27 \mathrm{NCD} 10$ steel plate. Dimensions of the projectile and the target are respectively $20 \mathrm{~mm}$ diameter, $50 \mathrm{~mm}$ length and $60 \mathrm{~mm}$ diameter, $20 \mathrm{~mm}$ thickness. A VISAR interferometer has been used to measure the free surface velocity of the rear of the plate. The measured profile velocity which is presented in figure 1, shows a compression wave composed of the elastic precursor and the plastic wave. The inflexion in the first portion of the unloading profile is due to the polymorphic transition of the steel. The successive reloading and unloading waves which follow are the trace of the damage in the target.

\section{RESULTS AND DISCUSSION}

The model of the polymorphic transition and the damage model previously presented were implemented in the hydrodynamic lagrangian code EPIC2. This code discretizes the equations of the continuum mechanics by the finite elements approach. The simulation of the above experiment was done with a mesh size of $0.25 \mathrm{~mm}$. The mesh is triangular with four triangles by cell. The deviatoric behaviour of the steel is reproduced by an elastic perfectly plastic model. Yield stress is $1.15 \mathrm{GPa}$ and shear modulus $81.3 \mathrm{GPa}$.

\subsection{Inflence on stress distribution}

In order to investigate the effect of the polymorphic transition on the stress distribution, simulations have been realised without damage model. Isopressure contours thus obtained are presented in figure 2 and figure 3 at a time of $2.8 \mu$ s after impact. These results show that the pressure decreases faster in the impactor and the target when the polymorphic transition is neglected. We observed that the area delimited by the $11.0 \mathrm{GPa}$ isopressure contour is more important when the polymorphic transition is taken into account. Also apparent are the shorter intervals between the isopressure contours when the polymorphic transition is not considered.

These different results are due to the specific wave structure of the polymorphic transition. In the studied configuration the value of impact stress which is higher than the $13.0 \mathrm{GPa}$ stress transition, leads to the formation of a two-waves structure in the impactor and the target (three-wave structure if elastic precursor is taken into account). In the same way, the release waves coming from the free surface near the interface between the impactor and the target, present a two-wave structure. The first is a smooth 
unloading wave and the second is a rarefaction shock wave. In the present geometrical configuration, the combination of multiple loading shocks and unloading waves produces a nearly square stress wave pulse near the axis of symmetry of the configuration. When the polymorphic transition is omitted, only a single shock wave followed by a smooth release wave is generated after the impact. In this case, the stress profile consists in a nearly triangular pulse.

Isopressure contours at a time of $4.5 \mu$ s after impact are shown in figure 4 and figure 5 respectively with and without the polymorphic transition. At this time, the maximum pressure in the projectile and in the target is about $5.0 \mathrm{GPa}$, so that the steel has retained its initially martensitic microstructure. Comparison between these two results shows the effects of the polymorphic transition on the tension zones. When the polymorphic transition is omitted, tension zones are localized near the back free surface of the target and relatively far from the impact interface in the impactor. In contrast, these tension zones are concentrated near the impact interface when the polymorphic transition is considered. These different repartitions of the tension areas are due to the specific shape of the compressive stress waves : a triangular pulse in the first case and a square pulse in the second.

\subsection{Influence on damage}

In order to evaluate the level of damage, we performed the same simulation as above, with the damage model presented in $\$ 2.2$ associated with the polymorphic transition model. The result of this simulation which is presented in figure 6, shows that the maximum level of damage is localized in the projectile and is 0.20 . In the target, the level of damage is less than 0.10 . Previous studies on the behaviour of this $27 \mathrm{NCD} 10$ steel have shown that complete spalling occurs at a level of damage between 0.25 and 0.30 . Thus, the results of the simulation indicate clearly that the impactor and the target are only partially damaged near the impact interface.

We compared in figure 1 the experimental free surface velocity profile with calculated profiles obtained with and without the polymorphic transition model. The dashed profile corresponds to the result of a calculation performed without the polymorphic transition and without damage. The dashed-dotted profile has been obtained with these two models. This comparison shows that the experimental profile is well reproduced when the two models are taken into account. Particularly, all the details of the experimental profile are present in the dashed-dotted profile and not in the dashed profile. The main differences concern the rise time of the compressive waves, the maximum velocity value and the final velocity value. The first two are due to the mesh size used for the computations and can be reduced by using a thinner mesh, but with an increasing calculation time. The difference in final velocity is probably due to the rupture of the target by adiabatic shear deformation.

The fact that the polymorphic transition in steel greatly influences its damage behaviour has been reported previously by Bertholf et al. [14] for hypervelocity impact. In opposition to our conclusions, they found that the polymorphic transition lead to an increase of damage by spalling in their configuration. This suggests that the effects of the polymorphic transition may be very different according to the studied configurations. In this sense, numerical calculation presents a real advantage to investigate and understand the physical mechanisms which occur during impact phenomena.

\section{CONCLUSION}

Computations performed with and without a polymorphic transition model showed the effects of this phenomenon for the impact of a $27 \mathrm{NCD} 10$ steel projectile on a $27 \mathrm{NCD} 10$ steel target at $1280 \mathrm{~m} / \mathrm{s}$. Numerical results obtained with the lagrangian code EPIC2 show the influence of the polymorphic transition on the stress distribution and tension zones in the target and in the projectile. Good agreement between experimental and calculated free surface velocity profiles is obtained with the polymorphic transition and damage models taken into account. In order to improve the accuracy of the computations, it would be essential to consider more sophisticated damage models which are able to reproduce anisotropic microcracking induced by spalling and by localisation of shear deformation. 


\section{ACKNOWLEDGEMENT}

We want to acknowledge P. Leyde for his help in the use of EPIC2 code and J. Picard for the experimental data.

\section{REFERENCES}

[1] Bancroft D., Peterson E.L. and Minshall F.S., J. Appl. Phys. 27 (1956) p. 291

[2] Shockey D.A. Curran D.R. and De Carli P.S., J. Appl. Phys. 46 (1975) pp. 3766-3775

[3] Hauver G. and Melani A, B R L report ARBRL-MR-02909 (1979)

[4] Gust H., Steinberg D.J. and Young D.A., High Temp. High Press. 11 (1979) pp. 271-280

[5] Horie Y. and Duvall G.E., in Proceedings of the Army Symposium on Solid Mechanics (1968)

[6] Andrews D.J., J. Phys. Chem. Solids 34 (1973) pp. 825-840

[7] Forbes J.W., Ph. D. Thesis, Washington State University, Pullman (1976)

[8] Duvall D.E. and Graham R.A., Rev. Mod. Phys. 49 (1977) p. 253

[9] Hereil P.L. and Doubax F., "Shock-induced polymorphic transition in steel", APS Topical Conference on Shock Compression of Condensed Matter, Williamsburg USA june 1991 (North Holland, 1992) pp. 17-20

[10] Doubax F., Ph. D. Thesis, Université Paul Sabatier de Toulouse (1992)

[11] Fanget A, Hereil P.L. and Sibeaud J.M., "The influence of shock induced polymorphic transition in steel on 2D waves propagation", APS Topical Conference on Shock Compression of Condensed Matter, Colorado Springs USA 1993 (Proceedings to be published)

[12] Curran D.R, Seaman L. and Shockey D.A., Physics Reports (1985)

[13] Johnson J.N., J. Appl. Phys. 52 (1981) pp. 2812-2825

[14] Bertholf L.D., Buxton L.D., Thorne B.J., Byers R.K., Stevens A.L. and Thompson S.L., J. Appl. Phys. 46 (1975) pp. 3776-3783

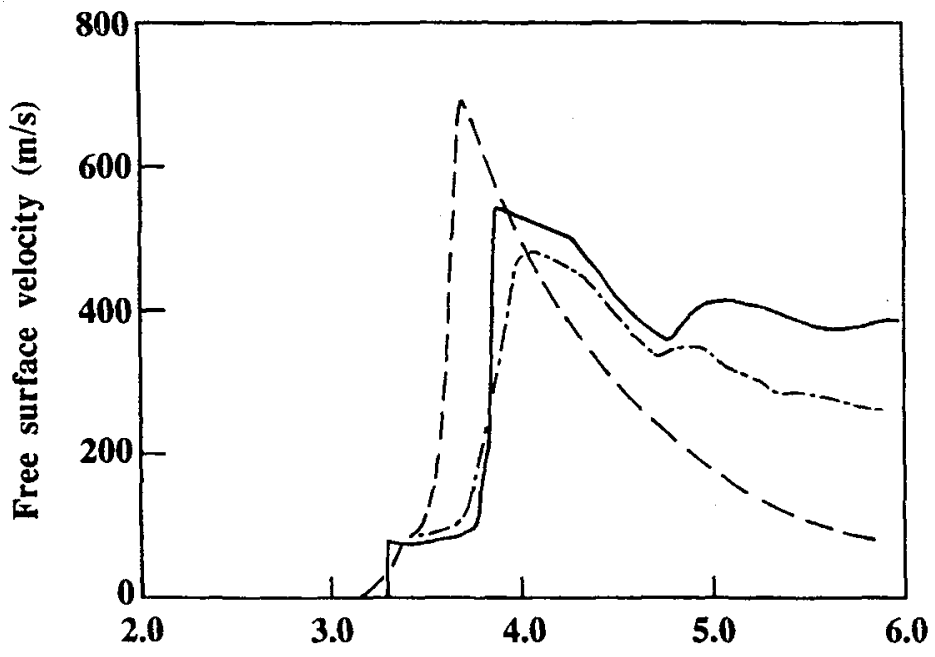

Time ( $\mu$ s)

Figure I : Comparison between experimental and calculated free surface velocity profiles.

Solid line : experimental

Dashed dotted line : calculation with polymorphic transition and damage models

Dashed line : calculation without polymorphic transition and damage models 


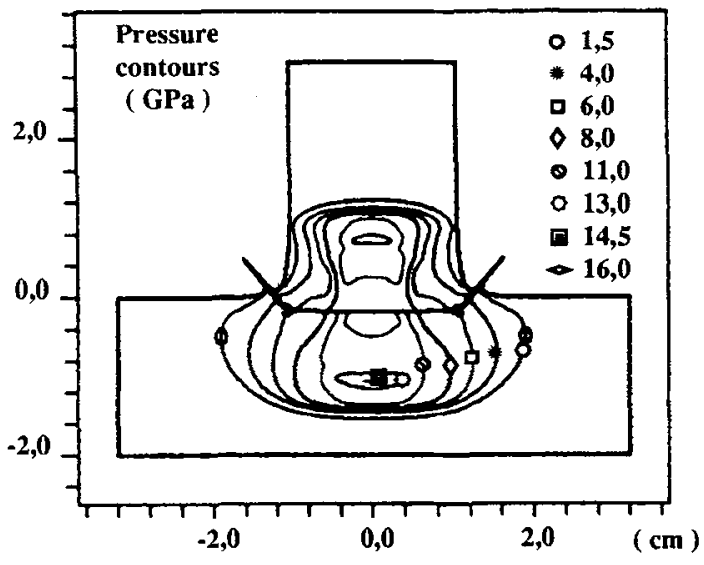

Figure 2 : Isopressure contours at time $2.8 \mu \mathrm{s}$ with polymorphic transition.

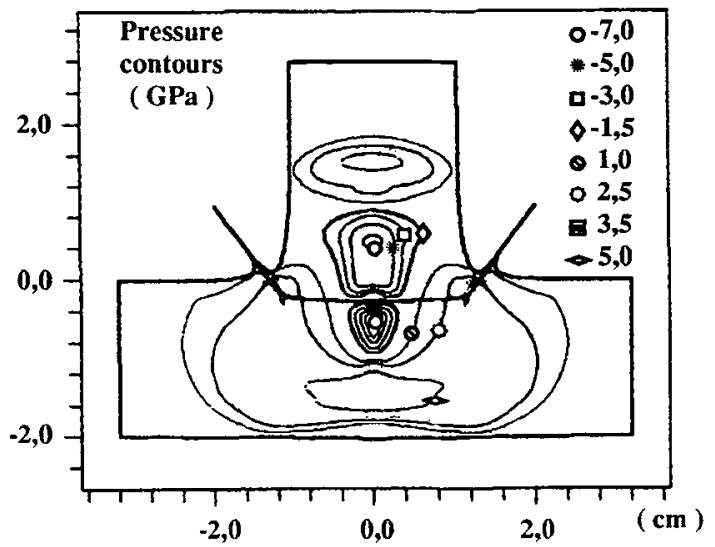

Figure 4 : Isopressure contours at time $4.5 \mu \mathrm{s}$ with polymorphic transition.

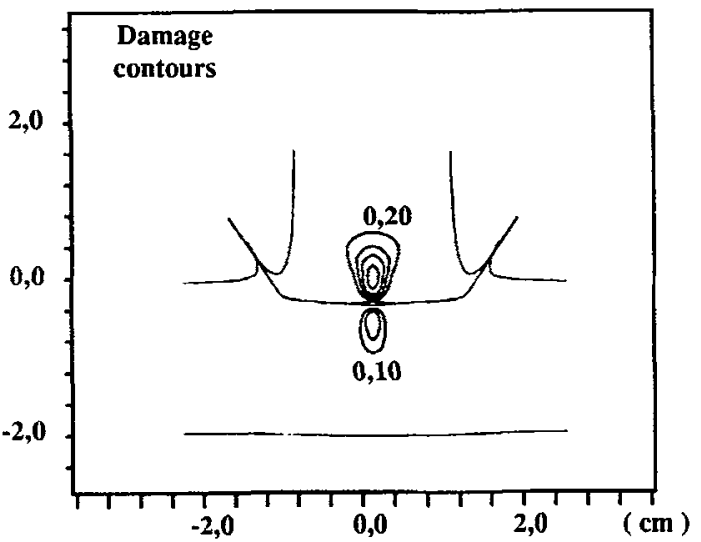

Figure 6 : Isodamage contours at time $4.5 \mu \mathrm{s}$ with polymorphic transition.

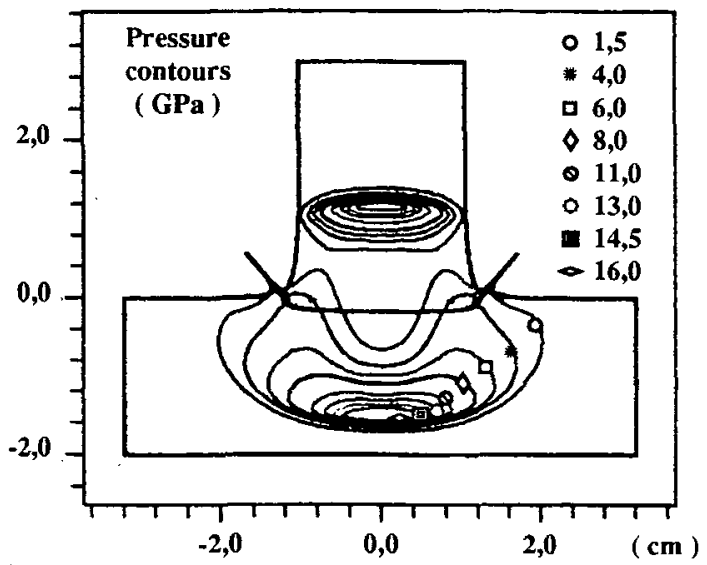

Figure 3 : Isopressure contours at time $2.8 \mu$ s without polymorphic transition.

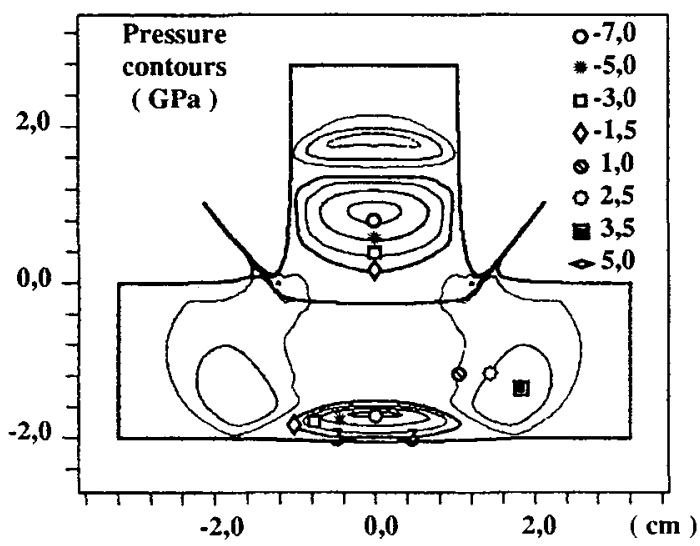

Figure 5 : Isopressure contours at time $4.5 \mu \mathrm{s}$ without polymorphic transition. 